\title{
FAKTOR-FAKTOR YANG BERHUBUNGAN DENGAN KEAKTIFAN KADER POSYANDU DI KELURAHAN 26 ILIR KECAMATAN BUKIT KECIL PALEMBANG TAHUN 2017
}

\author{
Hamyatri Rawalilah \\ STIK Bina Husada di Palembang, Program Studi Kesehatan Masyarakat \\ Email: hamyatri_rawalillah@binahusada.ac.id
}

\begin{abstract}
ABSTRAK
Keaktifan kader Posyandu merupakan suatu perilaku atau tindakan nyata yang bisa dilihat dari keteraturan dan keterlibatan seorang kader dalam berbagai kegiatan Posyandu baik kegiatan di dalam maupun di luar Posyandu. Kehadiran kader begitu besar manfaatnya terhadap kegiatan posyandu, karena tanpa kader kegiatan posyandu tidak dapat berjalan dengan baik. Tujuan penelitian ini untuk menganalisis hubungan antara pendidikan, pengetahuan, pekerjaan, pelatihan, dan penghargaan dengan keaktifan kader Posyandu. Jenis penelitian ini adalah kuantitatif dengan pendekatan deskriptif analitik metode Cross Sectional. Teknik pengumpulan data adalah dengan menggunakan kuisioner, dengan 35 sampel kader Posyandu. Penelitian ini dilaksanakan di Posyandu Kelurahan 26 Ilir Palembang pada bulan Januari 2018. Hasil penelitian ini ada 16 responden kader Posyandu yang aktif sedangkan ada 19 responden kader Posyandu yang kurang aktif. Didapatkan nilai $p$ value untuk masing-masing variabel independen, yaitu pendidikan $(\mathrm{p}=0,005)$, pengetahuan $(\mathrm{p}=0,017)$, pelatihan $(0,001)$, pekerjaan $(\mathrm{p}=0,005)$, penghargaan $(\mathrm{p}=0,001)$, ada hubungan antara pendidikan, pengetahuan, pekerjaan, pelatihan dan penghargaan dengan keaktifan kader Posyandu di Kelurahan 26 Ilir Palembang tahun 2017. Berdasarkan hasil Penelitian disarankan Petugas Puskesmas dapat menambah pengetahuan kader, melengkapi sarana Posyandu, dan memberikan penghargaan Kader Posyandu agar Kader Posyandu akan lebih aktif lagi dalam kegiatan Posyandu untuk memberikan pelayanan kesehatan di Posyandu.
\end{abstract}

\section{Kata Kunci: Keaktifan Kader, Posyandu, Kelurahan}

\begin{abstract}
The level of the activeness of a Posyandu cadre is a behavior or concrete action that can be seen from the regularity and involvement of a cadre in various Posyandu activities both inside and outside the Posyandu. The presence of cadres is of great benefit to the activities of the posyandu, because without a cadre the activities of the posyandu cannot run well. The purpose of this study was to analyze the relationship between education, knowledge, work, training, and rewards with the activeness of Posyandu cadres. This type of research was quantitative with an analytical descriptive approach to the Cross Sectional method. The technique of collecting data was by using questionnaires, with 35 Posyandu cadre samples. This research was carried out at Posyandu, 26 Ilir Palembang in January 2018. The results of this study were 16 active Posyandu cadre respondents while 19 Posyandu cadres were less active. $P$ value was obtained for each independent variable, namely education ( $p$ $=0.005)$, knowledge $(p=0.017)$, training $(0.001)$, employment $(p=0.005)$, rewards $(p=0.001)$, relationship between education, knowledge, work, training and rewards with the activeness of Posyandu cadres in the 26 Ilir Palembang Village in 2017. Based on the results of the study, it was suggested that Puskesmas officers could increase cadre knowledge, complete Posyandu facilities, and give Posyandu Cadre rewards so that Posyandu cadres were Posyandu activities to provide health services at the Posyandu.
\end{abstract}

Keywords: Level of the activeness of cadres, Posyandu, Urban Village 


\section{Pendahuluan}

\subsection{Latar Belakang}

Sumberdaya manusia yang sehat dan berkualitas merupakan modal utama atau investasi dalam pembangunan kesehatan. Kesehatan bersama-sama dengan pendidikan ekonomi merupakan tiga pilar yang sangat mempengaruhi kualitas sumberdaya manusia. Dalam laporan UNDP tahun 2011 menunjukan bahwa pada tahun 2011 Indeks Pembangunan Manusia (IPM) Indonesia yaitu sebesar 0,617 dan menduduki peringkat 124 dari 187 negara (Kemenkes RI, 2011).

Sejalan dengan perkembangan paradigma pembangunan, telah ditetapkan arah kebijakan pembangunan kesehatan, yang tertuang dalam Rencana Pembangunan Jangka Menengah (RPJM) 2010-2014 Bidang Kesehatan. Kondisi pembangunan kesehatan diharapkan telah mampu mewujudkan kesejahteraan masyarakat yang tunjukan dengan membaiknya berbagai indikator pembangunan Sumber Daya Manusia, seperti: meningkatnya derajat kesejahteraan dari status gizi masyarakat, meningkatnya tumbuh kembang optimal, kesejahteraan dan perlindungan anak, terkendalinya jumlah dan laju pertumbuhan penduduk, serta menurunnya kesenjangan antar individu, antar kelompok masyarakat dan antar daerah dengan tetap lebih mengutamakan pada upaya preventif, promotif serta pemberdayaan masyarakat di bidang kesehatan adalah menumbuh kembangkan Posyandu (Depkes RI, 2006).

Posyandu merupakan salah satu bentuk Upaya Kesehatan Bersumber Daya Masyarakat (UKBM) yang dikelola dan diselenggarakan dari, oleh, untuk dan bersama masyarakat dalam penyelenggaraan pembangunan kesehatan, guna memberdayakan masyarakat dan memberikan kemudahan kepada masyarakat dalam memperoleh pelayanan kesehatan dasar, utamanya untuk mempercepat penurunan angka kematian ibu dan bayi ( Depkes RI, 2006).

Keberadaan posyandu sangat diperlukan oleh masyarakat dalam upaya promosi dan perlindungan terhadap kesehatan ibu dan anak. Peran dan dukungan Pemerintah kepada Posyandu melalui Puskesmas sangat penting untuk memfasilitasi pelaksanaan berbagai kegiatan kesehatan di Posyandu (Sutisna, 2011).

Dalam menjalankan tugasnya, para kader mendapat bantuan dari petugas kesehatan. Guna melaksanakan kegiatannya sebagai kader, maka terlebih dahulu diberikan latihan berupa keterampilan dan pengetahuan yang disesuaikan dengan tugas yang diemban dalam mengelola
Posyandu. Kader Posyandu sebaiknya mampu menjadi pengelola Posyandu, karena merekalah yang paling memahami kebutuhan masyarakat di wilayahnya. Tanpa kehadiran kader, kegiatan posyandu tidak dapat berjalan dengan baik. (Kemenkes RI, 2011).

Menurut Sugeng (2014), yang melakukan penelitian tentang faktor-faktor yang berhubungan dengan keaktifan kader Posyandu di wilayah kerja Puskesmas Rou Kota Serang Banten, menyatakan bahwa ada hubungan antara pengetahuan dan motivasi dengan keaktifan kader Posyandu. Selain itu, keaktifan kader Posyandu juga dipengaruhi oleh tingkat pendidikan dan penghargaan (Harisman, 2012).

Berdasarkan Profil Dinas Kesehatan Kota Palembang pada tahun 2013, jumlah Posyandu aktif adalah 1.003 Posyandu. Namun pada tahun 2014 jumlah Posyandu aktif di Palembang menurun menjadi 627 Posyandu. Sedangkan tahun 2015 Posyandu aktif hanya berjumlah 670 Posyandu. Dari hasil observasi awal dan wawancara dengan warga masyarakat Kelurahan 26 Ilir didapatkan bahwa pada waktu pelaksanaan Posyandu masih ada para kader yang tidak hadir untuk melaksanakan tugasnya. Dari data tersebut, maka peneliti tertarik untuk melakukan penelitian mengenai Faktor-faktor yang berhubungan dengan keaktifan kader Posyandu di Kelurahan 26 Ilir Kecamatan Bukit Kecil Palembang Tahun 2017.

\subsection{Tujuan Penelitian}

Penelitian ini bertujuan untuk diketahuinya faktor-faktor yang berhubungan dengan keaktifan kader Posyandu di Kelurahan 26 Ilir Kecamatan Bukit Kecil Palembang Tahun 2017.

\section{Metode Penelitian}

Desain Penelitian dalam penelitian ini adalah jenis penelitian kuantitatif dengan pendekatan Deskriptif Analitik metode Cross Sectional. Survey analitik adalah survey atau penelitian yang menggali bagaimana dan mengapa fenomena kesehatan itu terjadi, kemudian dilakukan analisis dinamika korelasi antara fenomena maupun antar faktor efek dengan cara pendekatan, observasi atau pengumpulan data sekaligus pada suatu saat (point time approach) melalui pengujian hipotesa dengan menganalisa data yang ada. Dalam hal ini peneliti berusaha memahami serta menganalisis faktor-faktor yang mempengaruhi keaktifan Kader Posyandu di Kelurahan 26 Ilir Kecamatan Bukit Kecil Palembang. 
Penelitian ini dilakukan pada Bulan Januari Tahun 2018 bertempat di Posyandu Kelurahan 26 Ilir Kecamatan Bukit Kecil Palembang dengan populasi seluruh Kader yang bekerja pada Posyandu tersebut yang berjumlah 35 orang Kader. Karena populasi kurang dari 100 makai sampel akan diambil secara keseluruhan (Total Sampling).

Teknik pengumpulan data dalam penelitian ini didapatkan dengan cara membagikan kuesioner. Kemudian data yang didapat dianalisis secara univariat dan bivariat dengan menggunakan uji chi square $(\alpha=0,05)$.

\section{Hasil dan Pembahasan}

\subsection{Hasil Analisis Bivariat}

Penelitian ini mengarnbil data dari hasil kuesioner yang didistribusikan oleh peneliti terhadap faktor-faktor yang berhubungan dengan keaktifan kader Posyandu di Kelurahan 26 Ilir Kecamatan Bukit Kecil Palembang Tahun 2017. Faktor-faktor tersebut meliputi hubungan pendidikan dengan keaktifan kader Posyandu, hubungan pengetahuan dengan keaktifan kader Posyandu, hubungan pelatihan dengan keaktifan kader Posyandu, hubungan pekerjaan dengan keaktifan kader Posyandu, dan hubungan penghargaan dengan keaktifan kader Posyandu diuraikan sebagai berikut ini.

\subsubsection{Hubungan Pendidikan dengan Keaktifan Kader Posyandu}

Berdasarkan penelitian yang telah dilaksanakan, hubungan antara pendidikan dengan keaktifan kader Posyandu dapat dilihat pada tabel 1 di bawah ini.

\section{Tabel 1}

Hubungan antara Pendidikan dengan Keaktifan Kader Posyandu di Kelurahan 26 Ilir Palembang Tahun 2017

\begin{tabular}{|c|c|c|c|c|c|c|}
\hline \multirow{3}{*}{ Pendidikan } & \multicolumn{4}{|c|}{ Keaktifan Kader } & \multirow{2}{*}{ Aktif } & \multicolumn{2}{|c|}{$\begin{array}{c}\text { Tidak } \\
\text { Aktif }\end{array}$} & Total & \multirow{2}{*}{\begin{tabular}{c} 
Value \\
\cline { 2 - 6 }
\end{tabular}} & \multicolumn{2}{|c|}{ N } & $\%$ & $\mathrm{~N}$ & $\%$ & & \\
\cline { 2 - 6 } & & & \\
\hline Tinggi & 6 & 100 & 0 & 0 & 6 & \\
\hline Rendah & 10 & 34,5 & 19 & 65,5 & 29 & \\
\hline Total & 16 & & 19 & & 35 & \\
\hline
\end{tabular}

Tabel diatas menunjukkan bahwa responden yang berpendidikan tinggi yang aktif sebanyak 6 orang $(100 \%)$, tidak ada responden yang berpendidikan tinggi yang tidak aktif. Sedangkan responden yang berpendidikan rendah yang aktif adalah sebanyak 10 orang (34,5\%), dan ada 19 orang responden yang berpendidikan rendah yang tidak aktif $(65,5 \%)$. Sedangkan nilai $p$ Value $=0,005$.

\subsubsection{Hubungan Pengetahuan dengan Keaktifan Kader Posyandu}

Berdasarkan penelitian yang telah dilaksanakan, hubungan antara pengetahuan dengan keaktifan kader Posyandu dapat dilihat pada tabel 2 di bawah ini.

\section{Tabel 2}

Hubungan antara Pengetahuan dengan

Keaktifan Kader Posyandu di Kelurahan 26 Ilir Palembang Tahun 2017

\begin{tabular}{|c|c|c|c|c|c|c|}
\hline \multirow{3}{*}{ Pengetahuan } & \multicolumn{4}{|c|}{ Keaktifan Kader } & \multirow{3}{*}{ Total } & \multirow{2}{*}{$\begin{array}{c}\text { P- } \\
\text { Value }\end{array}$} \\
\hline & \multicolumn{2}{|c|}{ Aktif } & \multicolumn{2}{|c|}{$\begin{array}{l}\text { Tidak } \\
\text { Aktif } \\
\end{array}$} & & \\
\hline & $\mathrm{N}$ & $\%$ & $\mathrm{~N}$ & $\%$ & & \\
\hline Baik & 16 & 55,2 & 13 & 44,8 & 29 & \\
\hline Kurang & 0 & 0 & 6 & 100 & 6 & 0.017 \\
\hline Total & 16 & & 19 & & 35 & \\
\hline
\end{tabular}

Tabel 2 diatas menunjukkan bahwa ada sebanyak $16(55,2 \%)$ responden pengetahuan baik yang aktif, dan ada 13 orang $(44,8 \%)$ resonden berpengetahuan baik yang tidak aktif. Sedangkan tidak ada $(0 \%)$ responden pengetahuan kurang yang aktif, dan responden pengetahuan kurang yang tidak aktif sebanyak 6 orang $(100 \%)$ responden. Nilai $p$ Value yang diperoleh adalah 0,017 .

\subsubsection{Hubungan Pelatihan dengan Keaktifan Kader Posyandu}

Berdasarkan hasil penelitian yang telah dilaksanakan, hubungan antara pelatihan dengan keaktifan kader Posyandu dapat dilihat pada tabel 3 di bawah ini.

Tabel 3

Hubungan antara Pelatihan dengan Keaktifan Kader Posyandu di Kelurahan 26 Ilir Palembang Tahun 2017

\begin{tabular}{|c|c|c|c|c|c|c|}
\hline \multirow{2}{*}{ Pelatihan } & \multicolumn{4}{|c|}{ Keaktifan Kader } & \multirow{2}{*}{ Aktif } & \multicolumn{2}{|c|}{$\begin{array}{c}\text { Tidak } \\
\text { Aktif }\end{array}$} & Total & \multirow{2}{*}{\begin{tabular}{l} 
V- \\
\cline { 2 - 6 }
\end{tabular}} & $\mathrm{n}$ & $\%$ & $\mathrm{~N}$ & $\%$ & & \\
\cline { 2 - 6 } & 16 & 84,2 & 3 & 15,8 & 19 & \multirow{2}{*}{0.001} \\
\hline $\begin{array}{c}\text { Ada } \\
\text { Adak }\end{array}$ & 0 & 0 & 16 & 100 & 16 & \\
\hline total & 16 & & 19 & & 35 & \\
\hline
\end{tabular}

Tabel diatas menunjukkan bahwa responden yang memiliki pelatihan yang aktif adalah sebanyak 16 orang $(84,2 \%)$, dan ada sebanyak 3 orang $(15,8 \%)$ responden yang memiliki pelatihan yang tidak aktif. Sedangkan tidak ada responden (0\%) 
yang tidak mendapatkan pelatihan yang aktif, dan ada sebanyak 16 orang (100\%) yang tidak memiliki pelatihan yang tidak aktif. Nilai $p$ Value yang diperoleh adalah 0,001 .

\subsubsection{Hubungan Pekerjaan dengan Keaktifan Kader Posyandu}

Berdasarkan hasil penelitian yang telah dilaksanakan, hubungan antara pekerjaan dengan keaktifan kader Posyandu dapat dilihat pada tabel 4 di bawah ini.

Tabel. 4

Hubungan antara Pekerjaan dengan

Keaktifan Kader Posyandu di Kelurahan 26 Ilir Palembang Tahun 2017

\begin{tabular}{|c|c|c|c|c|c|c|}
\hline \multirow{2}{*}{ Pekerjaan } & \multicolumn{4}{|c|}{ Keaktifan Kader } & \multirow{2}{*}{ Aktif } & \multicolumn{2}{|c|}{$\begin{array}{c}\text { Tidak } \\
\text { Aktif }\end{array}$} & \multirow{2}{*}{$\begin{array}{c}\text { Total } \\
\text { Value }\end{array}$} \\
\cline { 2 - 6 } & $\mathrm{n}$ & $\%$ & $\mathrm{~N}$ & $\%$ & & \\
\hline Bekerja & 4 & 100 & 0 & 0 & 4 & \multirow{2}{*}{0.035} \\
\hline $\begin{array}{l}\text { Tidak } \\
\text { Bekerja }\end{array}$ & 12 & 38,7 & 19 & 61,3 & 31 & \\
\hline total & 16 & & 19 & & 35 & \\
\hline
\end{tabular}

Tabel 4 diatas menunjukkan bahwa responden yang bekerja dan aktif adalah sebanyak 4 orang (100\%), dan tidak ada responden yang bekerja yang tidak aktif (0\%). Sedangkan responden yang tidak bekerja dan aktif adalah sebanyak 12 orang $(38,7 \%)$, dan responden yang tidak bekerja dan tidak aktif adalah sebanyak 19 orang $(61,3 \%)$ responden. Nilai $p$ Value yang diperoleh adalah 0,035 .

\subsubsection{Hubungan Penghargaan dengan Keaktifan Kader Posyandu}

Berdasarkan hasil penelitian yang telah dilaksanakan, hubungan antara penghargaan dengan keaktifan kader Posyandu dapat dilihat pada tabel 5 di bawah ini.

\section{Tabel 5}

Hubungan antara Penghargaan dengan Keaktifan Kader Posyandu di Kelurahan 26 Ilir Palembang Tahun 2017

\begin{tabular}{|c|c|c|c|c|c|c|}
\hline \multirow{3}{*}{ Penghargaan } & \multicolumn{4}{|c|}{ Keaktifan Kader } & \multirow{2}{*}{ Aktif } & \multicolumn{2}{|c|}{$\begin{array}{c}\text { Tidak } \\
\text { Aktif }\end{array}$} & Total & \multirow{2}{*}{\begin{tabular}{l} 
Value \\
\cline { 2 - 6 }
\end{tabular}} & $\mathrm{n}$ & $\%$ & $\mathrm{~N}$ & $\%$ & & \\
\cline { 2 - 6 } & 16 & 69,6 & 7 & 30,4 & 23 & \multirow{2}{*}{0.001} \\
\hline $\begin{array}{l}\text { Pernah } \\
\text { Pernak }\end{array}$ & 0 & 0 & 12 & 100 & 12 & \\
\hline \multicolumn{1}{|c|}{ total } & 16 & & 19 & & 35 & \\
\hline
\end{tabular}

Tabel 5 diatas menunjukkan bahwa ada sebanyak 16 orang $(69,6 \%)$ responden yang pernah menerima penghargaan yang aktif, dan ada sebanyak 7 orang $(30,4 \%)$ responden yang tidak pernah menerima penghargaan yang aktif. Sedangkan tidak ada (0\%) responden yang tidak pernah menerima penghargaan yang aktif, dan ada sebanyak aktif adalah sebanyak 12 orang (100\%) responden yang tidak pernah menerima penghargaan yang tidak aktif. Nilai $p$ Value yang diperoleh adalah 0,001 .

\subsection{Pembahasan}

\subsubsection{Hubungan Pendidikan dengan Keaktifan Kader Posyandu}

Terlihat pada tabel 1 bahwa nilai $p$ Value $=$ 0,005 . Jika dibandingkan dengan nilai $\alpha=0,05$, maka $p$ Value $>0,05$, disimpulkan ada hubungan pendidikan kader posyandu dengan keaktifan kader posyandu di Kelurahan 26 Ilir Palembang tahun 2017.

Hasil ini tidak sejalan dengan penelitian Hanum (2015) terhadap keaktifan kader posyandu di wilayah kerja puskesmas slawi, yang menyatakan bahwa pendidikan tidak berpengaruh yang signifikan terhadap keaktifan kader posyandu $p$ value $=0,355$.

Dari teori tersebut, dapat dikatakan bahwa kader dengan tingkat pendidikan tinggi akan cenderung untuk lebih banyak tahu daripada yang mempunyai pendidikan rendah, pendidikan yang tinggi memudahkan seseorang untuk menerima dan memberikan pengetahuan, sikap, serta perilaku. Maka peneliti berpendapat bahwa pendidikan sudah sesuai dengan apa yang diharapkan. Secara umum terdapat kecendrungan yang baik, dikarenakan kader Posyandu sudah sesuai memiliki pendidikan yang termasuk kategori tinggi.

\subsubsection{Hubungan Pengetahuan dengan Keaktifan Kader Posyandu}

Terlihat pada tabel 2 bahwa nilai $p$ Value $=$ 0,017 . Jika dibandingkan dengan nilai $\alpha=0,05$, maka $p$ Value $<0,05$, disimpulkan ada hubungan pengetahuan kader posyandu dengan keaktifan kader posyandu di Kelurahan 26 Ilir Palembang tahun 2017.

Pengetahuan merupakan hasil dari tahu dan ini terjadi setelah orang melakukan penginderaan terhadap suatu obyek tertentu.Penginderaan terjadi melalui panca indera manusia yaitu indera penglihatan, pendengaran, penciuman, rasa dan raba.Sebagian besar pengetahuan manusia diperoleh melalui mata dan 
telinga. Pengetahuan atau kognitif merupakan domain yang sangat penting dalam bentuk tindakan seseorang (Notoatmojo, 2010)

Pengetahuan mencakup 6 tingkat dan untuk kader Posyandu ini berdasarkan hasil telah berada pada tingkat yang keenam yaitu evaluasi, dimana kader Posyandu telah mampu mengaplikasikan hal yang diketahuinya dan telah mampu membuat penilaian seperti membandingkan status gizi bayi dengan menggunakan Kartu Menuju Sehat (KMS). Pengetahuan sangat penting dalam memberikan pengaruh terhadap sikap dan tingkah laku kader terhadap pemeliharan kesehatan masyarakat, terutama bagi pelayanan kesehataan bayi dan balita.Oleh karena itu, pengetahuan tentang posyandu sangat diperlukan.

Hasil ini sejalan dengan penelitian Hanum (2015) terhadap keaktifan kader posyandu di wilayah kerja Puskesmas Slawi, yang menyatakan bahwa pendidikan berpengaruh yang signifikan terhadap keaktifan kader posyandu $p$ Value $=0,001$.

\subsubsection{Hubungan Pelatihan dengan Keaktifan Kader Posyandu}

Terlihat pada tabel 3 bahwa nilai $p$ Value $=$ 0,001 yang jika dibandingkan dengan nilai $\alpha=$ 0,05 , maka $p$ Value $>0,05$, maka dapat disimpulkan bahwa ada hubungan pelatihan kader posyandu dengan keaktifan kader Posyandu di Kelurahan 26 Ilir Palembang tahun 2017.

Pelatihan kader merupakan salah satu kegiatan yang penting dalam rangka mempersiapkan kader agar mau dan mampu berperan serta dalam melaksanakan kegiatan UPGK/Posyandu di desanya. Kader yang mempunyai ketrampilan serta pengabdian yang tinggi dalam melaksanakan tugasnya adalah merupakan kunci keberhasilan kegiaatan UPGK/Posyandu. Oleh karena itu pengetahuan dan keterampilan kader yang diperlukan harus disesuaikan dengan tugas mereka dalam melaksanakan dan menembangkan kegiatan UPGK/Posyandu tersebut (Kemenkes RI, 2011).

Hasil ini sejalan dengan penelitian Endra (2012) terhadap keaktifan kader posyandu di wilayah UPT Puskesmas Ngembal Kulon Kabupaten Kudusyang menyatakan bahwa pelatihan ada berpengaruh yang signifikan terhadap keaktifan kader posyandu $p$ Value $=0,006$.

Berdasarkan hasil penelitian dan teori terkait, pelatihan kader merupakan salah satu kegiatan yang penting dalam rangka mempersiapkan kader agar mau dan mampu berperan serta dalam melaksanakan kegiatan UPGK/Posyandu di desanya. Maka peneliti berpendapat bahwa pelatihan sudah sesuai dengan apa yang diharapkan, karena kader Posyandu sudah sesuai dan diberikan pelatihan.

\subsubsection{Hubungan Pekerjaan dengan Keaktifan Kader Posyandu}

Terlihat pada tabel 4 bahwa didapatkan $p$ Value $=0,035$, jika dibandingkan dengan nilai $\alpha=$ 0,05 , maka $p$ Value $<0,05$, disimpulkan bahwa ada hubungan pekerjaan kader posyandu dengan keaktifan kader di Kelurahan 26 Ilir Palembang tahun 2017.

Pekerjaan adalah tugas utama atau kegatan rutinitas yang dimiliki oleh seorang kader untuk membantu, dan membiayai kehidupan keluarga serta menunjang kebutuhan rumah tangganya. Pekerjaan juga dapat mempengaruhi seseorang didalam menjaga kesehatan, baik individu maupun kesehatan keluarga. Karakteristik yang berhubungan dengan pekerjaan karena kesibukan membuat seseorang terabaikan akan kesehatannya, termasuk kader Posyandu. Kesibukan akan pekerjaan terkadang membuat ibu lupa terhadap tugas dan tanggungjawab yang dibebankan kepadanya. Sebaiknya seorang kader Posyandu itu tidak memiliki pekerjaan yang tetap, dan mempunyai pengalaman yang lama menjadi kader dan tidak adanya pergantian kader dalam satu tahun (Sugianto, 2005).

Di dapatkan $p$ Value $=0,035$ yang jika dibandingkan dengan nilai $\alpha=0,05$, maka $p$ Value $<0,05$, disimpulkan bahwa ada hubungan keaktifan kader dengan pekerjaan kader posyandu di Kelurahan 26 Ilir Palembang tahun 2017.

Berdasarkan hasil penelitian dan teori terkait terlihat bahwa terdapat hubungan antara jenis pekerjaan dan keaktifan sebagai kader, misalnya saja seorang ibu yang dengan kesibukan tertentu akan mempengaruhi keaktifan kader tersebut didalam pelaksanaan Posyandu sesuai dengan jadwal yang telah ditentukan setiap bulannyaDisamping itu terlihat bahwa terdapat hubungan antara jenis pekerjaan dan keaktifan sebagai kader, misalnya saja seorang ibu yang dengan kesibukan tertentu akan mempengaruhi keaktifan kader tersebut didalam pelaksanaan Posyandu sesuai dengan jadwal yang telah ditentukan setiap bulannya.

\subsubsection{Hubungan Penghargaan dengan Keaktifan Kader Posyandu}

Terlihat pada tabel 3 bahwa nilai $p$ Value $=$ 0,001 , jika dibandingkan dengan nilai $\alpha=0,05$, maka $p$ Value < 0,05, dapat disimpulkan bahwa terdapat hubungan penghargaan kader Posyandu 
dengan keaktifan kader Posyandu di Kelurahan 26 Ilir Palembang tahun 2017.

Penghargaan kader adalah bisa dalam bentuk materil dan non materil yang diberikan kepada kader. Penghargaan berupa uang memberikan motivasi tersendiri bagi kader. Penghargaan merupakan daya tarik. Selain itu penghargaan dapat pula dijadikan sebagai motivasi kader untuk aktif dalam kegiatan Posyandu. Karena dengan adanya hal tersebut menangarah kepada rasa tanggung jawab, memiliki, otonomi dan keberanian dalam keaktifan kader Posyandu.

Hasil ini tidak sejalan dengan penelitian Desi (2013) terhadap keaktifan kader posyandu di Wilayah Kerja Puskesmas Peusangan Siblah Kruengyang menyatakan bahwa penghargaan berpengaruh yang signifikan terhadap keaktifan kader posyandu $p$ value $=0,005$.

Berdasarkan hasil penelitian dan teori terkait, penghargaan kader posyandu berupa uang memberikan motivasi tersendiri bagi kader, baik berupa materil maupun non materil. Penghargaan merupakan daya tarik, selain itu penghargaan dapat pula dijadikan sebagai motivasi kader untuk aktif dalam kegiatan Posyandu.

Maka peneliti berpendapat bahwa penghargaan Kader Posyandu merupakan salah satu hal yang terpenting didalam menunjang keaktifan kader melakukan tugasnya. Masih ada Kader yang belum mendapatkan penghargaan materil berupa uang, non materil berupa sertifikat, pin kader dll.

\section{Kesimpulan dan Saran}

\subsection{Kesimpulan}

Dari hasil penelitian dan pembahasan yang pada bab sebelumnya, maka peneliti menyimpulkan sebagai berikut:

a. Distribusi frekuensi kader Posyandu yang aktif $(45,7 \%)$ di Kelurahan 26 Ilir Palembang tahun 2017.

b. Ada hubungan antara pendidikan dengan keaktifan kader Posyandu di Kelurahan 26 Ilir Palembang tahun 2017.

c. Ada hubungan antara pengetahuan dengan keaktifan kader Posyandu di Kelurahan 26 Ilir Palembang tahun 2017.

d. Ada hubungan antara pelatihan dengan keaktifan kader Posyandu di Kelurahan 26 Ilir Palembang tahun 2017.

e. Ada hubungan antara Pekerjaan dengan keaktifan kader Posyandu di Kelurahan 26 Ilir Palembang tahun 2017.

f. Ada hubungan antara penghargaan dengan keaktifan kader posyandu di Kelurahan 26 Ilir Palembang tahun 2017.

\subsection{Saran}

Berdasarkan kesimpulan diatas, penulis mengajukan saran-saran sebagai berikut:

a. Diharapkan pada Instansi terkait melalui petugas Puskesmas dapat menambah pengetahuan kepada para kader Posyandu, agar Kader Posyandu lebih aktif lagi dalam melaksanakan pelayananan kegiatan Posyandu.

b. Diharapkan kepada petugas Puskesmas dapat memberikan pendidikan dan pelatihan Posyandu, agar kader Posyandu lebih aktif lagi dalam kegiatan Posyandu untuk memberikan pelayanan di Posyandu.

c. Diharapkan kepada instansi pemerintah melalui petugas Puskesmas dapat memberikan penghargaan kader bagi Kader Posyandu agar lebih aktif lagi dalam kegiatan Posyandu untuk memberikan pelayanan di Posyandu. 


\section{DAFTAR PUSTAKA}

Departemen Kesehatan Republik Indonesia, 2006. Pedoman Umum Pengelolaan Posyandu. Jakarta.

Desy Agustina. 2013. Faktor-Faktor yang Mempengaruhi Keaktifan Kader Posyandu Dalam Wilayah Kerja Puskesmas Peusangan Siblah Krueng Tahun 2013.

Endra Wibowo. 2012. Faktor-Faktor yang Berhubungan dengan Keaktifan Kader Posyandu di Wilayah UPT Puskesmas Ngembal Kulon Kabupaten Kudus Tahun 2012.

Hanum Tri Hapsari. 2015. Keaktifan Kader Posyandu di Wilayah Kerja Puskesmas Slawi Tahun 2015.

Kementerian Kesehatan Republik Indonesia. 2011. Pedoman Umum Pengelolaan Posyandu.

Kementerian Kesehatan Republik Indonesia. 2011. Rencan Pengembangan Tenaga Kesehatan 2011-2022. Jakarta.

Kementerian Kesehatan Republik Indonesia. 2011. Panduan Kader Posyandu. Jakarta.

Mubarak. 2012. Ilmu Kesehatan Masyarakat. Salemba Medika. Jakarta.

Notoatmodjo. 2010. Promosi Kesehatan Teori \& Aplikasi. Rineka Cipta. Jakarta

Manusia. RinekaCipta. Jakarta

Dinas kesehatan Kota Palembang. 2015. Profil Dinas Kesehatan Kota Palembang Tahun 2015. Palembang.

Sugeng. 2014. Faktor-Faktor yang Berhubungan dengan Keaktifan Kader Posyandu di Wilayah Kerja Puskesmas Rau Kota Serang Provinsi Banten Tahun 2014. Banten.

Sutisna. 2011. Manajemen Kesehatan Teori dan Praktik di Puskesmas. Gajah Mada University Press. Yogyakarta

Soegianto, Benny. 2005. Upaya Revitalisasi Posyandu. Jurnal Akademi Gizi Surabaya. Surabaya.

Sugiyono. 2012. Metode Penelitian Kuantiatif Kualitatif dan $R \& D$. Penerbit Alfabeta. Bandung
Syafarudin. 2009. Ilmu Kesehatan Masyarakat. Trans Info Media. Jakarta 